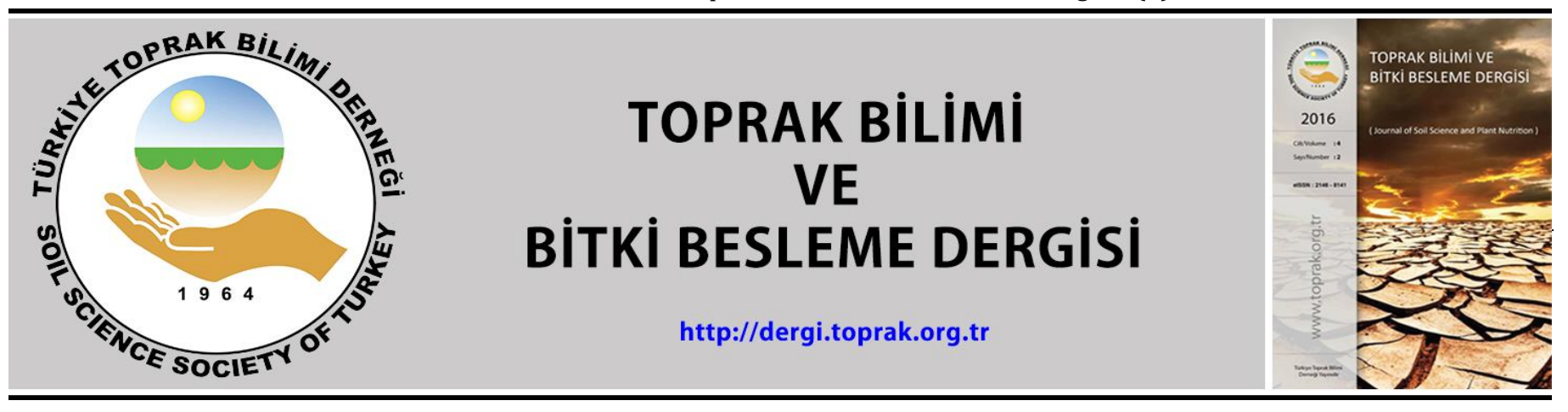

\title{
Türkiye'de sarımsak tarımı yapılan farklı yöre topraklarının selenyum içerikleri ve bazı temel toprak özellikleri arasındaki ilişkiler
}

\author{
Hanife Akça1, Murat Ali Turan², Nilgün Taban", Süleyman Taban1,* \\ Abdoul Rasmane Ouedraogo ${ }^{1}$, Nilüfer Türkmen ${ }^{3}$ \\ ${ }^{1}$ Ankara Üniversitesi Ziraat Fakültesi, Toprak Bilimi ve Bitki Besleme Bölümü, Ankara \\ ${ }^{2}$ Uludağ Üniversitesi Ziraat Fakültesi, Toprak Bilimi ve Bitki Besleme Bölümü, Bursa \\ ${ }^{3}$ Giresun Üniversitesi Dereli Meslek Yüksekokulu, Ormancllık Bölümü, Dereli, Giresun \\ 4 Ziraat Mühendisi, Ankara
}

\begin{abstract}
Özet
Ülkemizde sarımsak tarımında ilk sıralarda yer alan illerden alınan toprak örneklerinde bitkiye yarayışlı selenyum konsantrasyonları ile bazı temel toprak özellikleri arasındaki ilişkilerin belirlenmesinin amaçlandığı bu çalışmada, Balıkesir Kırklareli, Kahramanmaraş, Hatay, Antalya, Karaman, Muğla ve Kastamonu illerinden toplam 224 adet toprak örneği alınmıştır. Alınan toprak örneklerinde tekstür, pH, EC, kireç, organik madde ile bitkiye yarayıșlı selenyum analizleri yapılmıștır. Yapılan analizler sonucunda, farklı yörelerden alınan toprak örnekleri birlikte değerlendirildiğinde, bitkiye yarayışlı selenyum konsantrasyonlarının 1,31-27,83 $\mu \mathrm{g} \mathrm{kg-1}$ arasında değiştiği ve ortalama $13,45 \mu \mathrm{g} \mathrm{kg}^{-1}$ olduğu belirlenmiştir. Bitkiye yarayışlı ortalama selenyum konsantrasyonun en fazla Kastamonu $(27,83 \mu \mathrm{g} \mathrm{kg}-1)$, en az ise Hatay $\left(1,31 \mu \mathrm{g} \mathrm{kg}^{-1}\right)$ yöresi topraklarında olduğu belirlenmiştir. Sarımsak tarımı yapılan toprakların ağırlıklı olarak kil bünyeli, \% 53,57'sinin hafif alkali, EC yönünden sorun taşımadığı, \% 41,07'sinin çok ve çok fazla kireçli, \% 47,32'sinin ise az ve çok az organik madde içerdiği belirlenmiştir. Bitkiye yarayışlı selenyum konsantrasyonu ile toprak reaksiyonu arasında önemli pozitif ( $\left.\mathrm{r}=0,330^{* * *}\right)$, kireç ve organik madde miktarları arasında ise önemli negatif (sırasıyla $r=-0,260^{* * *}, r=-0,259^{* * *}$ ) ilişkiler belirlenmiştir. Toprakta reaksiyonun yükselmesi durumunda Se yarayışlılığının arttığı, buna karşın kireç ve organik maddenin artması durumunda ise Se yarayışlılığının azaldığı belirlenmiştir.
\end{abstract}

Anahtar Kelimeler: Sarımsak, selenyum, temel toprak özellikleri.

\section{The relationships among the some basic soil properties and selenium content of different region soils under garlic cultivation in Turkey}

\begin{abstract}
In this study, it is intended to determine the available selenium concentration of soil samples and the basic relationships among the basic soil properties of the areas in terms of garlic farming in Turkey. Total 224 soil samples were collected from Balıkesir, Kırklareli, Kahramanmaraş, Hatay, Antalya, Karaman, Muğla and Kastamonu provinces where garlic production is at the first place in our country. The soils sample texture, $\mathrm{pH}, \mathrm{EC}$, lime, organic matter and available selenium analyses were determined. As a result of garlic cultivated soils analyses, the plant available selenium concentration in soil was varied between 1,31 and $27,83 \mu \mathrm{g} \mathrm{kg}-1$ with an average of $13,45 \mu \mathrm{g} \mathrm{kg}^{-1}$. It was found that the highest available selenium concentrations were in Kastamonu $(27,83 \mu \mathrm{g} \mathrm{kg}-1)$ and the lowest is in Hatay $\left(1,31 \mu \mathrm{g} \mathrm{kg}^{-1}\right)$ regions. The textural class was heavy clay, $53,57 \%$ of total samples was slightly alkaline, there was not any EC problem, 41,07 \% of total soil samples was high and very high lime and 47,32\% of soil samples were low and very low in organic matter. Based on the correlation analysis; positive relations ( $\mathrm{r}=0,330^{* * *}$ ) between available selenium concentrationsoil reaction and negative relations (respectively $r=-0,260^{* * *}, r=-0,259^{* * *}$ ) between lime-organic matter were determined. It was determined that Se availability increases with the rising $\mathrm{pH}$ value, whereas Se availability decreases with the increasing of lime and organic matter.
\end{abstract}

Keywords: Garlic, selenium, basic soil properties.

(C) 2019 Türkiye Toprak Bilimi Derneği. Her Hakkı Saklıdır

* Sorumlu yazar:

Tel. : : $\quad 03125961390$

E-posta : taban@agri.ankara.edu.tr
Geliş Tarihi : 28 Kasım 2018

Kabul Tarihi : 21 Nisan 2019
e-ISSN

DOI : $10.33409 /$ tbbbd.595214 


\section{Giriş}

Selenyum (Se) insan ve hayvanlar için mutlak gerekli bir elementtir (Miller ve ark., 1991; Campen, 1991). Selenyum noksanlığında tüm hayvanlarda ve özellikle gençlerinde beyaz kas hastalığı (white muscle disease), besinsel kas distrofisi (nutritional muscle dystrophy) ya da üreme bozukluğu (reproductive disorder) gibi sağlık sorunları oluşmaktadır (Miller ve ark., 1991). Selenyumun kanser riskini azaltması, yaşlanmayı önlemesi gibi işlevleri insan sağlığı açısından da büyük önem taşımaktadır.

Topraklarda Se eksikliğinin yaygın olması, insanlarda ciddi beslenme ve sağlık sorunları yaratmaktadır. İnsan ve hayvan sağlığı için son derece önemli olması nedeniyle selenyumun besin zincirine gübre olarak dahil edilmesi, topraktan hayvanlara ve insanlara olan döngüsünde anahtar rol oynamaktadır (Terry ve Zayed, 1998). Gerçekten de selenyumca zenginleștirilmiş bitkisel ürünlerin yetiștirilmesi büyük bir önem taşımaktadır (Zhu ve ark., 2017).

Selenyum bitkiler için mutlak gerekli element olmamasına karşın kimi araştırıcılar tarafından az miktarda selenyumun bitkilerde gelişmeyi teşvik ettiği saptanmıştır (Perkins ve King, 1938; Trelease ve Trelease, 1938; Scharrer ve Schropp, 1950). Günümüzde bitkisel üretimde yaygın biçimde selenyumlu gübre uygulaması yapılmadığı göz önüne alındığında, toprakta bitkiye yarayışlı (ekstrakte edilebilir) Se konsantrasyonu ile yarayışlılığa etki eden bazı temel toprak özelliklerinin ortaya konulması önemli olmaktadır.

Çoğunlukla toprakların toplam Se içerikleri 0,1-2,0 $\mathrm{mg} \mathrm{kg}^{-1}$ arasında ve ortalama 0,3 $\mathrm{mg} \mathrm{kg}^{-1} \mathrm{iken}$, selenifer toprakların Se içerikleri çok daha yüksek olup 2,0 ile 10,0 $\mathrm{mg} \mathrm{kg}^{-1}$ arasında değiştiği bildirilmektedir (Kacar ve Katkat, 1998). Topraklarda; elementel selenyum $\left(\mathrm{Se}^{0}\right)$, selenyum $\left(\mathrm{Se}^{-2}\right)$, selenit $\left(\mathrm{SeO}_{3}{ }^{-2}\right)$, selenat $\left(\mathrm{SeO}_{4}^{-2}\right)$ ve selenoamino asit gibi organik selenyum bileşikleri olmak üzere beş değişik formda bulunan selenyum kimyasal özellikleri bakımından Kükürt'e (S) benzerlik göstermekte ve yarı kurak bölge topraklarında kükürt ile kalkopirit, bornit ve pirit gibi bileşikler oluşturmuş şekilde bulunmaktadır (Kacar ve Katkat, 1998).

Selenyum, asidik ve nötr pH'ya sahip topraklarda selenit $\left(\mathrm{SeO}_{3}{ }^{-2}\right)$ formunda bulunurken, alkalin reaksiyona sahip topraklarda selenat $\left(\mathrm{SeO}_{4}^{-2}\right)$ formunda bulunmaktadır. Suda çözünürlükleri yüksek olan selenatlar $\left(\mathrm{SeO}_{4}^{-2}\right)$ bitkiler tarafından kolaylıkla alınmaktadır (Kacar ve Katkat, 1998). Asit reaksiyonlu topraklara kireç uygulandığında ise Se hareketlenmekte ve selenit $\left(\mathrm{SeO}_{3}{ }^{-2}\right)$ formundan selenat $\left(\mathrm{SeO}_{4}{ }^{-2}\right)$ formuna dönüşerek bitkilere yarayışlı hale geçmektedir (Kudryevsev ve Andreyev, 1969). Bitkiler geliştikleri ortamdan selenyumu temelde selenat $\left(\mathrm{SeO}_{4}^{-2}\right)$ iyonları şeklinde almaktadır. Selenit $\left(\mathrm{SeO}_{3}{ }^{-2}\right)$ iyonu şeklinde alınan selenyum miktarı ise çok düşüktür (Banuelos ve Meek, 1989). Bitkiler selenatı $\left(\mathrm{SeO}_{4}^{-2}\right)$ aktif sülfat $\left(\mathrm{SO}_{4}{ }^{-2}\right)$ alımına benzer şekilde almakta (Bryant ve Laishley, 1988) ve bu iki iyon bitki köklerindeki aynı bağlanma noktaları için yarışmakta ve toprakta sülfat konsantrasyonu arttığında bitkiler tarafından selenat alımında önemli oranda azalma olmaktadır (Mikkelsen ve Wan, 1990; Zayed ve Terry, 1992). Kükürt bitkideki Se birikimini etkilemektedir. Topraklara elementel S, sülfat veya jips ilavesi bitkinin selenat alımını azaltmaktadır (Hurd-Karrer, 1938; Mikkelsen ve ark., 1989). Bunun aksine bitki metabolizmasında Se, kükürdün yerine geçme yeteneğindedir (Trelease ve ark., 1960).

Selenyumun topraklardaki hareketi toprak nemiyle yakından ilişkilidir. Yalnız nemli ve alkali topraklarda selenyum selenata oksitlenmektedir. Az yağmur alan bölgelerdeki yüksek pH'lı topraklarda selenyum $\mathrm{CaSeO}_{3}$ (Ca-Selenit) şeklinde bulunmaktadır. Ca-selenit suda çok iyi çözünmekte ve bitkiler bunu kolaylıkla kullanabilmektedir (Halilova, 2004). Bununla birlikte killer selenyumu bağlamakta ve böylece aynı Se düzeyinde kumlu topraklara nazaran daha düşük Se ile bitkiyi destekleme yeteneği göstermektedir (Davis ve ark., 2006).

Toprakta organik madde miktarı ile selenyum yarayışlılığı arasında antagonistik ilişki vardır. Toprakta organik maddenin azalması ve pH'nın artması durumunda suda çözünebilen Se miktarı da artmaktadır. Floor ve ark. (2011) organik maddece zengin asidik topraklarda Se yarayışlılığının daha az olduğunu, özellikle topraktaki toplam selenyumun düşük olması halinde toprak organik maddesinin Se yarayışlılığını belirgin olarak engellediğini bildirmişlerdir.

Bitkiler, topraktaki Se miktarı ile direk ilişkili olarak Se biriktirmektedirler. Örneğin, Amerika'da normal koşullarda yetiştirilen buğday 0,2-0,4 $\mathrm{mg} \mathrm{kg}^{-1}$ Se içerirken, selenyumca zengin topraklarda yetişen buğday 5$15 \mathrm{mg} \mathrm{kg}^{-1}$ Se içerebilmektedir (Olson ve ark., 1970).

Toprakta bulunan selenyum yarayışlılığı üzerine toprak reaksiyonu, kireçleme, diğer elementlerin konsantrasyonları ve iklim koşulları etkili olmaktadır. Bitkiler, topraktaki Se miktarına bağlı olarak Se 
biriktirmektedirler. Sarımsak hiper akümülatör bitki olup, bazı koşullarda 1000 mg kg-1ª kadar selenyumu bünyesinde biriktirebilmektedir (Ip ve ark., 2000; Finley, 2005). Selenyumca zengin sarımsakların diğer sarımsaklara oranla daha fazla antikanserojen etkiye sahip oldukları bilinmektedir (Ip ve Lisk, 1994). Dolayısı ile sarımsak tarımı yapılan toprakların selenyum konsantrasyonları ne kadar fazla ise o topraklarda yetiştirilen sarımsakların da hem besin değeri hem de antikansorejen etkileri artmaktadır. Sarımsaktaki önemli Se bileşiklerinden olan Se-metil selenosistein ve $\gamma$-glutamil-Se-metil selenosisteinin benzer mekanizmalarda antikanser ajanı oldukları bildirilmiștir (Yan Dong ve ark., 2001).

Ülkemizde tarım yapılan toprakların ve bitkilerin selenyum içeriklerinin belirlenmesine yönelik yapılan çalışmalar yok denecek kadar azdır. Bu nedenle tarım topraklarımızın ve bitkilerimizin selenyum içerikleri hakkında yeterince bilgi sahibi değiliz. Bu çalışmada, ülkemizde sarımsak tarımında ilk sıralarda yer alan illerden alınan toprak örneklerinde bitkiye yarayışlı selenyum konsantrasyonları ile bazı temel toprak özellikleri ile arasındaki ilişkilerin belirlenmesi amaçlanmıştır.

\section{Materyal ve Yöntem}

Toprak örnekleri, ülkemizde sarımsak tarımında ekim alanı ve üretim bakımından ilk sıralarda yer alan Kastamonu (81), Kırklareli (41), Antalya (23), Kahramanmaraş (21), Muğla (20), Balıkesir (17), Hatay (12) ve Karaman (9) olmak üzere 8 farklı ilden sarımsak ekim alanları dikkate alınarak toplam 224 toprak örneği sarımsak haşatından sonra (2009 yılı Ekim-Kasım ayı içerisinde) alınmıştır. Alınan toprak örneklerinde; tekstür, hidrometre yöntemine göre (Bouyoucos, 1951); toprak reaksiyonu (pH), saf su ile 1:2,5 oranında sulandırılmış toprak örneklerinde Grewelling ve Peech (1960)'e göre; kalsiyum karbonat, Hızalan ve Ünal (1966)'a göre; elektriksel iletkenlik (EC), 1:2.5 oranında sulandırılmış toprak örneklerinde Anonymous (1951)'e göre; organik madde, Jackson (1962) tarafından bildirildiği şekilde değiștirilmiş Walkley-Black yaș yakma yöntemine göre belirlenmiştir. Bitkiye yarayışlı selenyum, Soltanpour (1991)'e göre 0,005M DTPA içerisinde $1 \mathrm{M} \mathrm{NH}_{4} \mathrm{HCO}_{3}$ (AB-DTPA, pH 7,6) çözeltisi ile ekstrakte edilen ve çözelti fazına geçen selenyum ICP-OES (Inductively Coupled Plasma-Optical Emission Spectrometry, Perkin Elmer Model DV 2100) cihazı ile belirlenmiştir.

Araştırma alanlarından alınan topraklarda belirlenen bitkiye yarayışlı selenyum konsantrasyonları ile bazı toprak özellikleri arasındaki ilişkiler (korelasyon) MINITAB (Minitab 17.1.0) paket programı ile hesaplanmıștır.

\section{Bulgular ve Tartışma}

Türkiye'de sarımsak tarımının ağırlıklı olarak en fazla yapıldığı 8 ilden alınan toprak örneklerinde bitkiye yarayışlı selenyum konsantrasyonlarının 1,31 ile 27,83 $\mu \mathrm{g} \mathrm{kg}^{-1}$ arasında değiştiği ve ortalama 13,45 $\mu \mathrm{g} \mathrm{kg}^{-1}$ olduğu belirlenmiştir (Çizelge 1).

Çizelge 1. Sarımsak tarımı yapılan alanlardan alınan toprak örneklerinin bitkiye yarayışlı selenyumun illere göre en düşük, en yüksek ve ortalama konsantrasyonları

\begin{tabular}{lccc}
\hline & & Se $\left(\mu \mathrm{kg}^{-1}\right)$ & Ortalama \\
\hline İller & En Düșük & En Yüksek & 17,10 \\
Balıkesir (17)* & 12,87 & 21,58 & 9,32 \\
Kırklareli (41) & 3,90 & 12,67 & 5,66 \\
Kahramanmaraş (21) & 2,68 & 6,94 & 1,76 \\
Hatay (12) & 1,31 & 2,24 & 8,44 \\
Antalya (23) & 5,93 & 10,46 & 12,33 \\
Karaman (9) & 4,14 & 14,53 & 4,16 \\
Muğla (20) & 1,54 & 5,04 & 22,34 \\
Kastamonu (81) & 11,09 & 27,83 & 13,45 \\
\hline Genel (224) & 1,31 & 27,83 & \\
\hline
\end{tabular}

*Alınan toprak örneği sayısı

Araştırma kapsamında alınan topraklarda ortalama bitkiye yarayışlı selenyum konsantrasyonunun en yüksek Kastamonu yöresi topraklarında $(27,83 \mu \mathrm{g} \mathrm{kg}-1)$, en düşük ise Hatay yöresi topraklarında $(1,31 \mu \mathrm{g} \mathrm{kg}$ 1) olduğu belirlenmiştir. Bitkiye yarayışlı selenyum konsantrasyonlarının Balıkesir yöresi topraklarında 12,87-21,58 $\mu \mathrm{g} \mathrm{kg}-1$ aralığında ve ortalama 17,10 $\mu \mathrm{g} \mathrm{kg}-1$, Kırklareli yöresinde 3,90-12,67 $\mu \mathrm{g} \mathrm{kg-1}$ aralı̆̆ında ve ortalama 9,32 $\mu \mathrm{g} \mathrm{kg}^{-1}$, Kahramanmaraş yöresinde 2,68-6,94 $\mu \mathrm{g} \mathrm{kg}^{-1}$ aralığında ve ortalama 5,66 $\mu \mathrm{g} \mathrm{kg}^{-1}$, Hatay yöresinde 1,31-2,24 $\mu \mathrm{g} \mathrm{kg}-1$ aralığında ve ortalama $1,76 \mu \mathrm{g} \mathrm{kg}-1$, Antalya yöresinde 5,93-10,46 $\mu \mathrm{g} \mathrm{kg}^{-1}$ aralığında ve ortalama 8,44 $\mu \mathrm{g} \mathrm{kg-1}$, Karaman yöresinde 4,14-14,53 $\mu \mathrm{g} \mathrm{kg-1}$ aralığında ve ortalama 12,33 $\mu \mathrm{g}$ $\mathrm{kg}^{-1}$, Muğla yöresinde 1,54-5,04 $\mu \mathrm{g} \mathrm{kg}-1$ aralığında ve ortalama 4,16 $\mu \mathrm{g} \mathrm{kg}-1$ ve Kastamonu yöresinde ise 11,09$27,83 \mu \mathrm{g} \mathrm{kg-1}$ aralığında ve ortalama 22,34 $\mu \mathrm{g} \mathrm{kg-1}$ olduğu saptanmıştır (Çizelge 1). Harmankaya (2009) 
tarafından Orta Anadolu Bölgesinde Konya (123 örnek), Niğde (31 örnek) ve Nevşehir (19 örnek) illerinden alınan toplam 173 toprak örnekleri ile yürüttüğü çalıșmada; toprakların elverișli Se konsantrasyonlarının 0,56-9,76 $\mu \mathrm{g} \mathrm{kg}^{-1}$ arasında değișim gösterdiği ve ortalama 2,25 $\mathrm{\mu g} \mathrm{kg}^{-1}$ olduğu, Konya ilinden alınan toprak örneklerinin Se konsantrasyonlarının 0,84-9,76 $\mu \mathrm{g} \mathrm{kg-1}$, Niğde ilinden alınan toprak örneklerinin Se konsantrasyonlarının 1,12-5,84 $\mu \mathrm{g} \quad \mathrm{kg}^{-1}$ ve Nevşehir ilinden alınan toprak örneklerinin Se konsantrasyonlarının 0,56-3,44 $\mu \mathrm{g} \mathrm{kg-1}$ arasında değişim gösterdiği ve sırasıyla ortalama 2,38, 2,36 ve 1,29 $\mu \mathrm{g} \mathrm{kg}{ }^{-1}$ olduğu saptanmıştır. Dünya genelinde toprakların selenyum içeriklerinin 0,1 ve $2 \mathrm{mg} \mathrm{kg}^{-1}$ aralığında değiştiği bildirilmektedir (Pezzarossa ve Petruzzelli, 2001). Araştırmacılar çeşitli ülke topraklarında Se noksanlıklarının yaygın olduğunu, ve çeşitli ülkelerin topraklarının Se içeriklerinin Çin'de 0,03-1,42 mg kg-1 (Zhang ve ark., 2008), İskoçya'da 0,11-0,88 mg kg-1 (Fordyce ve ark., 2010), Japonya'da 0,05-2,80 mg kg-1 (Yamada ve ark., 2009) ve İspanya'da 0,01-2,7 mg kg-1 aralıklarında değiștiğini belirlemişlerdir (Gabos ve ark., 2014). Irmak ve Semercioğlu (2012), Çukurova yöresinde yaygın olarak buğday yetiştirilen 30 farklı alandan aldıkları toprak örneklerinde yarayışlı selenyum konsantrasyonunu 2,84 $\mu \mathrm{g} \mathrm{kg}^{-1}$ ile $19,31 \mu \mathrm{g} \mathrm{kg}-1$ arasında değiştiğini ve ortalama $11,40 \mu \mathrm{g} \mathrm{kg}{ }^{-1}$ olduğunu rapor etmişlerdir. Toprakların Se içeriği oluştuğu ana materyalin Se içeriğine bağlıdır. Selenyum özellikle sedimenter kayalardan oluşan topraklarda daha fazla bulunur. Volkanik aktiviteler boyunca Se'un büyük bir kısmı yüksek sıcaklıkta uçucu gazlar şeklinde sızmakta ve bu yüzden volkanik kayalar genellikle düşük düzeyde Se içermektedirler (Mayland ve ark., 1989). Topraklarda bitkiye yarayışlı selenyum konsantrasyonun $<50 \mu \mathrm{g} \mathrm{kg}-1$ olduğu (Davis ve ark., 2006) göz önünde bulundurulduğunda sarımsak tarımının ağırlıklı olarak en fazla yapıldığı 8 ilden alınan toprakların (Kastamonu, Kırklareli, Antalya, Kahramanmaraş, Muğla, Balıkesir, Hatay ve Karaman) bitkiye yarayışlı selenyum konsantrasyonlarının oldukça düşük olduğu ortaya konulmuştur. Türkiye'de sarımsak tarımının yoğun yapıldığı 8 ilden alınan toprakların önemli bir bölümünü kil tekstürlü (toplamın \% 49,1'i) topraklar oluşturmakta olup bunu, killi tın (\% 22,3), kumlu killi tın $(\% 19,2)$ ve diğer $(\% 9,4)$ tekstür sınıflı topraklar takip etmektedir. İllere göre tekstür dağılımı incelendiğinde; Balıkesir, Kırklareli, Kahramanmaraş, Hatay, Kastamonu illerinde başat tekstür sınıfının kil, Antalya'da killi tın ve Karaman ve Muğla'da ise kumlu killi tın tekstür olduğu belirlenmiştir (Çizelge 2).

Çizelge 2. Sarımsak tarımı yapılan alanlardan alınan toprak örneklerinin tekstür, pH, EC, kireç ve organik madde içeriklerinin illere göre en düşük, en yüksek ve ortalama değerleri

\begin{tabular}{|c|c|c|c|c|c|c|c|c|}
\hline İller & Değerler & Kum (\%) & Silt (\%) & Kil (\%) & $\mathrm{pH}$ & $\mathrm{EC}\left(\mathrm{mS} \mathrm{cm}^{-1}\right)$ & Kireç (\%) & Org. Mad. (\%) \\
\hline \multirow{3}{*}{$\begin{array}{l}\text { Balıkesir } \\
(17)^{*}\end{array}$} & En Düşük & 17,28 & 13,00 & 32,72 & 6,95 & 0,13 & 3,12 & 1,42 \\
\hline & En Yüksek & 47,28 & 36,00 & 62,72 & 8,13 & 0,22 & 34,35 & 3,59 \\
\hline & Ortalama & 31,38 & 19,35 & 49,27 & 7,37 & 0,16 & 14,44 & 2,30 \\
\hline \multirow{3}{*}{$\begin{array}{l}\text { Kırklareli } \\
(41)\end{array}$} & En Düşük & 8,84 & 11,00 & 34,88 & 6,06 & 0,13 & 0,43 & 1,13 \\
\hline & En Yüksek & 46,12 & 46,00 & 70,00 & 8,04 & 0,46 & 18,45 & 3,26 \\
\hline & Ortalama & 29,61 & 17,71 & 52,68 & 6,99 & 0,23 & 5,39 & 2,26 \\
\hline \multirow{3}{*}{$\begin{array}{l}\text { Kahramanmaraş } \\
\text { (21) }\end{array}$} & En Düşük & 19,12 & 14,00 & 18,00 & 7,01 & 0,12 & 6,10 & 0,65 \\
\hline & En Yüksek & 65,00 & 32,00 & 52,00 & 7,89 & 0,31 & 32,59 & 7,57 \\
\hline & Ortalama & 40,28 & 24,76 & 34,95 & $\mathbf{7 , 4 2}$ & 0,17 & 18,89 & 2,55 \\
\hline \multirow{3}{*}{$\begin{array}{l}\text { Hatay } \\
(12)\end{array}$} & En Düşük & 19,12 & 6,00 & 10,72 & 7,22 & 0,15 & 7,67 & 0,38 \\
\hline & En Yüksek & 81,28 & 40,00 & 58,16 & 7,73 & 0,63 & 60,19 & 3,27 \\
\hline & Ortalama & 40,90 & 23,25 & 35,85 & 7,46 & 0,29 & 31,73 & 1,92 \\
\hline \multirow{3}{*}{$\begin{array}{l}\text { Antalya } \\
\text { (23) }\end{array}$} & En Düşük & 22,12 & 7,00 & 16,72 & 6,10 & 0,14 & 2,26 & 1,07 \\
\hline & En Yüksek & 69,28 & 40,00 & 50,88 & 7,95 & 0,65 & 54,48 & 7,03 \\
\hline & Ortalama & 42,31 & 24,74 & 32,95 & 7,22 & 0,26 & 30,75 & 2,57 \\
\hline \multirow{3}{*}{$\begin{array}{l}\text { Karaman } \\
\text { (9) }\end{array}$} & En Düşük & 21,84 & 8,00 & 26,16 & 7,71 & 0,13 & 4,52 & 0,67 \\
\hline & En Yüksek & 63,84 & 32,00 & 50,72 & 8,47 & 0,33 & 40,50 & 4,31 \\
\hline & Ortalama & 41,73 & 22,67 & 35,60 & 8,11 & 0,23 & 28,17 & 2,33 \\
\hline \multirow{3}{*}{$\begin{array}{l}\text { Muğla } \\
(20)\end{array}$} & En Düşük & 22,28 & 11,00 & 8,00 & 6,21 & 0,06 & 2,46 & 0,65 \\
\hline & En Yüksek & 74,00 & 37,00 & 58,72 & 8,51 & 0,35 & 47,42 & 7,73 \\
\hline & Ortalama & 44,57 & 26,40 & 29,03 & 7,66 & 0,21 & 19,16 & 3,25 \\
\hline \multirow{3}{*}{$\begin{array}{l}\text { Kastamonu } \\
\text { (81) }\end{array}$} & En Düşük & 20,00 & 10,00 & 22,00 & 7,10 & 0,12 & 1,54 & 0,17 \\
\hline & En Yüksek & 63,28 & 43,00 & 58,16 & 9,67 & 0,47 & 29,68 & 4,19 \\
\hline & Ortalama & 39,62 & 22,23 & 38,14 & 7,78 & 0,22 & 12,48 & 1,79 \\
\hline Genel & En Düşük & 8,84 & 6,00 & 8,00 & 6,06 & 0,058 & 4,33 & 1,73 \\
\hline \multirow{2}{*}{ (224) } & En Yüksek & 81,28 & 46,00 & 70,00 & 9,67 & 0,653 & 601,8 & 77,32 \\
\hline & Ortalama & 38,10 & 22,13 & 39,77 & 7,50 & 0,22 & 160,6 & 22,28 \\
\hline
\end{tabular}

* Alınan toprak örneği sayısı 
Toprak reaksiyonu illere göre incelendiğinde; ortalama reaksiyonun Balıkesir yöresinde pH 7,37, Kırklareli yöresinde pH 6,99, Kahramanmaraş yöresinde pH 7,42, Hatay yöresinde pH 7,46, Antalya yöresinde pH 7,22, Karaman yöresinde pH 8,11, Muğla yöresinde pH 7,66 ve Kastamonu yöresinde pH 7,78 olduğu saptanmıștır (Çizelge 2). Araştırma kapsamında alınan toprak örnekleri birlikte değerlendirildiğinde, toprakların \% 0,89'unda reaksiyonun kuvvetli alkali, \% 53,57'sinde hafif alkali, \% 41,96'sinda nötr ve \% 3,57'sinde ise hafif asit olduğu belirlenmiştir (Çizelge 3). Sarımsak tarımı için ideal toprak reaksiyonun pH 6-7 arası (Rosen ve ark., 1999) olduğu dikkate alındığında toprakların pH yönünden önemli bir sorun taşımadığı belirlenmiştir. Taşköprü'de sarımsak tarımı yapılan toprakların reaksiyonlarının (pH) 7,15 ile 7,86 arasında değiştiği ve genelde hafif alkali reaksiyonlu olduğu (Taban ve ark., 2004), Orta Anadolu'da çeltik yetiştirilen toprakların reaksiyonlarının ise $(\mathrm{pH})$ 5,83 ile 8,94 arasında değiştiği ve genelde toprakların hafif ve orta derecede alkali reaksiyonlu olduğu (Taban ve ark., 1997) belirlenmiştir. Akça ve ark. (2017), Ankara-Beypazarı yöresinde havuç tarımı yapılan alanlardan alınan toprak örneklerinde pH'nın 7,52-8,81 arasında değiştiği ve ortalama 8,13 olduğunu saptamışlardır. Li ve ark., (2017) toprakların pH içeriklerinin selenyum yarayışlılığını büyük ölçüde etkilediğini ve genel olarak toprak pH'sının düşük olduğu koşullarda selenyumu yarayışlılığının da azaldığını bildirmişlerdir (Johnsson, 1991; Johnson ve ark., 2000; Cao ve ark., 2001; Wang ve Gao, 2001; Sharma ve ark., 2015). Johnsson (1991), toprağın kil ve organik madde içeriği arttıkça pH'ın Se alımı üzerindeki etkisinin azaldığını bildirmiştir.

Çizelge 3. Sarımsak tarımı yapılan alanlardan alınan toprak örneklerinin pH, kireç, organik madde içeriklerinin yeterlik sınırlarına göre dağılımı

\begin{tabular}{cclc}
\hline & Sinır Değeri & Değerlendirme & Dağllım (\%) \\
\hline & $<4,5$ & Kuvvetli asit & 0 \\
pH & $4,5-5,5$ & Orta Asit & 0 \\
(Anonim, 1988) & $5,5-6,5$ & Hafif Asit & 3,57 \\
& $6,5-7,5$ & Nötr & 41,96 \\
& $7,5-8,5$ & Hafif Alkali & 53,57 \\
& $>8,5$ & Kuvvetli Alkali & 0,89 \\
\hline Kireç & $<1$ & Az Kireçli & 0,45 \\
$(\%)$ & $1-5$ & Kireçli & 21,43 \\
(Anonim, 1988) & $5-15$ & Orta Kireçli & 37,05 \\
& $15-25$ & Fazla Kireçli & 20,98 \\
Organik Madde & $>25$ & Çok Fazla Kireçli & 20,09 \\
(\%) & $<1$ & Çok Az & 8,48 \\
(Anonim, 1988) & $1-2$ & Az & 38,84 \\
& $2-3$ & Orta & 37,50 \\
\end{tabular}

Elektriksel iletkenlik yönünden bir sorunun taşımadığı belirlenen toprakların kireç içerikleri illere göre incelendiğinde; ortalama kireç içeriklerinin Balıkesir yöresinde \% 14,44, Kırklareli yöresinde \% 5,39, Kahramanmaraş yöresinde \% 18,89, Hatay yöresinde \% 31,73, Antalya yöresinde \% 30,75, Karaman yöresinde \% 28,17, Muğla yöresinde \% 19,16 ve Kastamonu yöresinde ise \% 12,48 olduğu saptanmıştır (Çizelge 2). Toprak örnekleri birlikte değerlendirildiğinde, toprakların \% 0,45'inin az kireçli, \% 21,43'ünün kireçli, \% 37,05'inin orta kireçli, \% 20,98'inin fazla kireçli ve \% 20,09'unun çok fazla kireçli olduğu belirlenmiştir (Çizelge 3). Topraklarda kireç miktarının yüksek olması başta fosfor ve çinko olmak üzere diğer mikro elementlerin yarayışlılığını olumsuz yönde etkilemesi yanında alınımlarını da güçleştirmektedir (Mengel ve Kirkby 1982, Udo ve ark., 1970, Kacar ve ark., 1998). Taşköprü (Kastamonu) yöresinde sarımsak tarımı yapılan toprakların \% 17,5'i kireçli, \% 60' ı orta kireçli ve \% 20'si fazla kireçli ve \% 2,5'i çok fazla kireçli olduğu belirlenmiştir (Taban ve ark., 20014). Taban ve ark. (1997), Orta Anadolu'da çeltik yetiştirilen toprakların kireç miktarları \% 0,88 ile \% 27,97 arasında değiştiğini ve toprakların \% 55'inin orta kireçli, \% 25'inin fazla kireçli ve \% 12,5'inin az kireçli olduğunu bildirmişlerdir. Ankara-Beypazarı havuç tarımı yapılan toprakların kireç içeriklerinin \% 1,19- 47,4 ve ortalama \% 18,8 olduğu Akça ve ark. (2017) tarafından rapor edilmiştir.

Sarımsak tarımı yapılan toprakların ortalama organik madde içeriklerinin Balıkesir yöresinde \% 2,30, Kırklareli \% 2,26, Kahramanmaraş yöresinde \% 2,55, Hatay yöresinde \% 1,92, Antalya yöresinde \% 2,57, Karaman yöresinde \% 2,33, Muğla yöresinde \% 3,25 ve Kastamonu yöresinde ise \% 1,79 olduğu tespit edilmiştir (Çizelge 2). Toprak örnekleri birlikte değerlendirildiğinde, organik madde yönünden toprakların \% 15,18'inin iyi, \% 37,50'sinin orta ve \% 47,32'sinin de az ve çok az düzeyde olduğu belirlenmiştir (Çizelge 
3). Topraklarda organik madde yetersizliği sarımsağın baş gelişimini olumsuz yönde etkilerken, beslenme problemine de neden olabilmektedir (Rosen ve ark., 1999). Taban ve ark., (2004) Taşköprü (Kastamonu) yöresinde sarımsak tarımı yapılan topraklarda organik madde içeriklerinin \% 1,38 ile \% 2,98 arasında değiştiğini ve toprakların Anonim (1988)'e göre \% 55'inin az \% 45'inin ise orta düzeyde organik madde içerdiklerini rapor etmişlerdir. Taban ve ark. (1997), Orta Anadolu'da çeltik tarımı yapılan toprakların organik madde içeriklerinin \% 0,73 ile \% 3,56 arasında; Akça ve ark. (2017) ise, Ankara-Beypazarı yöresinde havuç yetiştirilen toprakların organik madde içeriklerinin \% 0,15 ile \% 2,38 arasında değiştiğini bildirmişlerdir. Toprakta organik maddenin artması halinde bitkiye yarayışlı selenyumun azaldığı (Kudryevsev ve Andreyev, 1969) ve düşük konsantrasyonlarda selenyum içeren topraklarda organik maddenin selenyumu fikse ettiği ve yarayışlılığının azaldığı belirtilmiştir (Li ve ark., 2017). Toprak organik maddesi ile Se yarayışlılığı arasındaki negatif ilişki a) organik madde ilavesiyle topraktaki selenyumun indirgenmesini artıracak ve yarayışlılığını azaltacak toprak agregasyonun oluşturulmasıyla (Kausch ve ark., 2012; Kausch ve Pallud, 2013; Whalen ve ark., 2003); b) organik maddenin mikroorganizmalara karbon kaynağı sağlayarak mikrobiyal faaliyetlerin artması sonucu topraktaki selenyumun biyolojik olarak indirgenmesinin teşvik edilmesiyle (Dungan ve ark., 2002; Nguyen ve ark., 2016; Zhang ve Frankenberger, 2003) ve c) organik kökenli gübrelerin topraklara ilavesiyle bu materyallerin zengin hidroksil ve fenolik gruplara sahip olması nedeniyle Se adsorbsiyonunun artmasıyla (Park ve ark., 2011) açıklanmaktadır.

Se içerikleri ile $\mathrm{pH}$ arasında önemli pozitif $\left(\mathrm{r}=0,260^{* * *}\right)$, kireç ve organik madde ile önemli negatif ilişki (sırasiyla $r=-0,260^{* * *}, r=-0,259^{* * *}$ ) belirlenmiştir (Çizelge 4). Elde edilen bu sonuçlar Taban ve ark. (2013) ile benzerlik göstermektedir. Davis ve ark. (2006), selenyum toksisitesinin en yaygın, iklimin kurak ya da yarı kurak olduğu ve toprak pH'sının $>7$ olduğu koşullarda görüldüğünü bildirmişlerdir. Toprakta organik madde miktarı azalınca ve alkalilik artınca suda çözünebilen Se miktarı da artmaktadır. Asit topraklara kireç ilave edilince, Se hareketlenmekte ve bitkiler için yarayışlı hale geçmektedir (Kudryevsev ve Andreyev, 1969).

Çizelge 4. Toprak selenyum içerikleri ile bazı toprak özellikleri arasındaki ilișkiler (r)

\begin{tabular}{cccccccc}
\hline & Kum & Kil & Silt & $\mathrm{pH}$ & EC & Kireç & 0.M. \\
\hline $\mathrm{Se}$ & $-0,012^{\text {öd }}$ & $0,048^{\text {öd }}$ & $-0,061^{\text {od }}$ & $0,330^{* * *}$ & $-0,043^{\text {öd }}$ & $-0,260^{* * *}$ & $-0,259^{* * *}$ \\
\hline
\end{tabular}

öd önemli değil, ${ }^{* * *} \mathrm{p}<0,001$

\section{Sonuç}

Sarımsak tarımı yapılan toprakların ağırlıklı olarak kil bünyeli, \% 53,57'sinin hafif alkali, EC yönünden sorun taşımadığı, \% 41,07'sinin çok ve çok fazla kireçli, \% 47,32'sinin ise az ve çok az organik madde içerdiği belirlenmiştir. Araştırmaya konu olan yörelerden alınan topraklarda belirlenen bitkiye yarayışlı selenyum

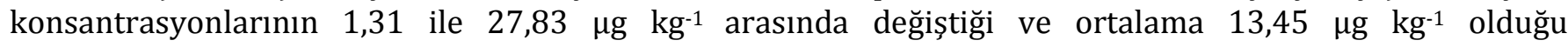
belirlenmiștir.

Bitkiye yarayışlı ortalama selenyum konsantrasyonunun en yüksek Kastamonu, en düşük ise Hatay yöresi topraklarında olduğu belirlenmiştir. Ülkemizde sarımsak tarımı yapılan illerden alınan sarımsak yumru örneklerinde belirlenen selenyum konsantrasyonunun Kastamonu-Taşköprü yöresinde yetiştirilen sarımsaklarda belirlenmiş olmasının (Turan ve ark., 2010) nedeni bu sonuçlar olmaktadır. pH'nın yükselmesi durumunda Se yarayışlılığının arttığı, buna karşın kireç ve organik maddenin artması durumunda ise Se yarayışlılığının azaldığı belirlenmiştir. Selenyumca zengin olan sarımsak yetiştiriciliğinde selenyum gübrelemesi önem arz etmektedir.

\section{Teşekkür}

Bu çalışma TUBİTAK 1040506 No'lu proje verileri kullanılarak hazırlanmıştır.

\section{Kaynaklar}

Akça H, Taşkın MB, Şahin Ö, Kaya EC, Turan MA, Taban S, Balcı M, 2017. Beypazarı yöresinde havuç (Daucus carota L.) tarımı yapılan toprakların verimlilik durumları ile havuç bitkisinin potansiyel beslenme sorunlarının belirlenmesi. Uludağ Üniversitesi Ziraat Fakültesi Dergisi 31(2):123-138.

Anonim, 1988. Türkiye gübreler ve gübreleme rehberi. Köy Hizmetleri Gen. Müd., Toprak ve Gübre Araştırma Ens. Müg. Genel Yayın No: 151, Teknik Yayınlar No: T-59, pp: 231.

Anonymous, 1951. Soil survey manual. Handbook No:18, U.S.D.A.

Banuelos GS, Meek DW, 1989. Selenium accumulation in selected vegetables, 1. Plant Nutrition 12, 1255-1272.

Bouyoucos GJ, 1951. A recalibration of hydrometer method for making mechanical analysis of soils. Agronomy Journal 43:434-438. 
Bryant RD, Laishley EJ, 1988. Evidence for two transporters of sulfur and selenium oxyanions in clostridium pasteurianum. Canadian Journal of Microbiology 34:700-703.

Campen van DR, 1991. Trace elements in human nutrition, micronutrients in agriculture, ed: Morvedt, J.J., Cox, F.R., Shuman, L.M., Welch, R.M., SSSA Book Series No: 4, Madison. WI. U.S.A. pp: 603-701.

Cao ZH,Wang XC, Yao DH, Zhang XL,Wong MH, 2001. Selenium geochemistry of paddy soils in Yangtze River Delta. Environment International 26:5, 335-339.

Davis JG, Steffens TJ, Engle TE, Mallow KL, Cotton SE, 2006. Diagnosing selenium toxicity. Colorado State University Extension Bulletin No: 6, 109:1-4.

Dungan RS, Yates SR, Frankenberger WT, 2002. Volatilization and degradation of soilapplied dimethylselenide. Journal of Environmental Quality 31(6):2045-2050.

Finley JW, 2005. Selenium accumulation in plant foods. Nutrition Reviews 63:196-202.

Floor GH, Calabrese S, Román-Ross G, Aiuppa A, 2011. Selenium mobilization in soils due to volcanic derived acid rain: an example from Mt Etna volcano, Sicily. Chemical Geology 289 (3): 235-244.

Grewelling T, Peech M, 1960. Chemical soil test. Cornell University Agricultural. Expt. Sta. Bull., No: 960.

Halilova H, 2004. Mikroelementlerin (I, Zn, Co, Mn, Cu, Se) biyojeokimyası. İlke-Emek Yayınları, Ankara, pp. 110.

Harmankaya M, 2009. Orta Anadolu Bölgesinde toprakların ve buğdayın selenyum düzeyinin belirlenmesi ve selenyum gübrelemesine farklı buğday genotiplerinin tepkisinin araştırılması. T.C. Selçuk Üniversitesi, Fen Bilimleri Enstitüsü, Toprak Anabilim Dalı (Yayınlanmamış Doktora Tezi).

Hızalan E, Ünal H, 1966. Topraklarda önemli kimyasal analizler. A.Ü. Ziraat Fakültesi Yayınları 278, pp: 88.

Hurd-Karrer AM, 1938. Relation of sulphate to selenium absorption by plants. American Journal of Botany 25:666-675.

Ip C, Birringer M, Block E, Kotrebai M, Tyson JF, Uden PC, Lisk DJ, 2000. Chemical speciation influences comparative activity of selenium-enriched garlic and yeast in mammary cancer prevention. Journal of Agricultural and Food Chemistry 48:2062-2070.

Ip C, Lisk DJ, 1994. Enrichment of selenium in allium vegetables for cancer prevention. Carcinogenesis, 15:1881-1885.

Irmak S, Semercioğlu T, 2012. Çukurova Bölgesi'nde yetiştirilen bazı buğday (Triticum Spp.) çeşitlerinde toprak-bitki selenyum içeriği arasındaki ilişki. Tarım Bilimleri Araştırma Dergisi 5(2):19-23.

Jackson ML, 1962. Soil chemical analysis. Prentice Hall. Inc. New York, pp. 498.

Johnson CC, Ge X, Green KA, Liu X, 2000. Selenium distribution in the local environment of selected villages of the Keshan Disease belt, Zhangjiakou District, Hebei Province, People's Republic of China. Applied Geochemistry 15(3):385-401.

Johnsson L, 1991. Selenium uptake by plants as a function of soil type, organic matter content and pH. Plant and Soil 133:57-64.

Kacar B, Katkat AV, 1998. Bitki besleme. Uludağ Üniversitesi Güçlendirme Vakfı Yayın No: 127, VİPAŞ Yayınları: 3, Bursa, pp. 594.

Kacar B, S Taban, M Alpaslan, G Fuleky, 1998. Zinc-phosphorus relationship in the dry matter yield and the uptake of zn, $\mathrm{p}$, fe and $\mathrm{mn}$ of rice plants (Otyza sativa L.) as affected by the total carbonate content of the soil. Second International Zinc Symposium. October 2-3, 1998, Ankara-Turkey.

Kausch M, Ng P, Ha J, Pallud C, 2012. Soil-aggregate-scale heterogeneity in microbial selenium reduction. Vadose Zone Journal 11(2).

Kausch MF, Pallud CE, 2013. Modeling the impact of soil aggregate size on selenium immobilization. Biogeosciences 10(3):1323-1336.

Kudryevsev AA, Andreyev MN, 1969. Bolezni nedostatoçnostı molodnyanca shjivotnih, ihprofilakticai leçeniye. Materiali dokladov Vsesoyuznoy Konferensii terapevtovi diagnostov posvyasennoy 100 letiyu prof. Ruhyadyeva T. I. Kazan.

Li Z, Liang D, Peng Q, Cui Z, Huang J, Lin Z, 2017. Interaction between selenium and soil organic matter and its impact on soil selenium bioavailability: A review. Geoderma 295:69-79.

Mayland HF, James LF, Panter KE, Sonderegger JL, 1989. Selenium in seleniferious environments. Selenium Agriculture and the Environment. (ed. L.W. Jacobs) Spec. Publ. 23. Soil Science of America, Madison, Wl. pp. 15-50.

Mengel K, Kirkby EA, 1982. Principles of plant nutrition. 3th ed, International Potash Institute,Worblaufen-Bern, Switzerland, pp: 655.

Mikkelsen RL, Page AL, Bingham FT, 1989. Factors affecting selenium accumulation by agricultural crops, selenium in agriculture and the environment. (eds. Jacobs LW) Amer. Soc. Agron. Soil Sci. Soc. Amer., Madison, Wis. pp. 65-94.

Mikkelsen RL, Wan HF, 1990. The effect of selenium on sulfur uptake by barley and rice. Plant and Soil 121:151-153.

Miller E, Lei RX, Ullrey DE, 1991. Trace elements in animal nutrition. Micronutrients in Agriculture 2 Ed, (eds. Mortvedt JJ, Cox FR, Shuman LM, Welch RM) SSSA Book Series No: 4. Madison, WI. USA., pp. 593-662.

Nguyen VK, Park Y, Yu J, Lee T, 2016. Microbial selenite reduction with organic carbon and electrode as sole electron donor by a bacteriumisolated fromdomesticwastewater. Bioresource Technoogy 212:182-189.

Olson OE, Novacek EJ, Whitehead EI, Palmer IS, 1970. Investigations on selenium in wheat. Phytochemistry 9:11811188.

Park JH, Lamb D, Paneerselvam P, Choppala G, Bolan N, Chung JW, 2011. Role of organic amendments on enhanced bioremediation of heavy metal (loid) contaminated soils. Journal of Hazardous Materials 185(2):549-574. 
Perkins AT, King HH, 1938. Selenium and tenmarg wheat. Jour. Amer. Soc. Agron. 30:664-667.

Rosen C, R Becker, V Fritz, B Hutchison, J Percich, C Tong, J. Wright, 1999. Growing garlic in Minnesota. http://www.Extension.umn.edu/distribution/cropsystems/components/7317-mulching.html

Scharrer K, Schropp W, 1950. Sand und wasserkulturversuche mit selen und tellur. Z. Pflanzenernahrung Düng. Bodenk. 50:187-202.

Sharma VK, McDonald TJ, Sohn M, Anquandah GA, Pettine M, Zboril R, 2015. Biogeochemistry of selenium. A review. Environmental Chemistry Letters 13(1):49-58.

Soltanpour PN, 1991. Determination of nutrient availability and elemental toxicity by AB-DTPA soil test and ICPS. Advance Soil Science 16:165-190.

Taban S, Alparslan M, Hashemi AG, Eken D, 1997. Orta Anadolu'da çeltik tarımı yapılan toprakların bazı fiziksel ve kimyasal özellikleri. Pamukkale Üniversitesi Mühendislik Bilimleri Dergisi 3(3):457-466.

Taban S, Çıkılı Y, Kebeci F, Taban N, Sezer SM, 2004. taşköprü yöresinde sarımsak tarımı yapılan toprakların verimlilik durumu ve potansiyel beslenme problemlerinin ortaya konulması. Ankara Üniversitesi Ziraat Fakültesi Tarım Bilimleri Dergisi 10 (3) 297-304.

Taban S, Turan MA, Sezer SM, Türkmen N, 2013. Kastamonu Taşköprü yöresinde yetiştirilen sarımsak bitkisinin selenyum içerikleri ve bazı toprak özellikleri arasındaki ilişkiler. Uudă̆ Üniversitesi Ziraat Fakültesi Dergisi 27(1):39-47

Terry N, Zayed AM, 1998. Phytoremediation of seleniurn. Environrnental Chernistry of Selenium. (eds. Frankenberger VVT Jr, Engberg RA) Marcel Dekker lnc, New York, pp. 633-655.

Trelease SF, DiSomma AA, Jacobs AL, 1960. Seleno-Amino acid found in Astragalus Bisulcatus, Science 132:6-18.

Trelease SF, Trelease HM, 1938. Selenium as a stimulating and possibly essential element for indicator plants. American Journal of Botany 25:372-380.

Turan MA, Taban N, Türkmen N, Taban S, 2010. Selenium concentration of garlic bulbs grown in different parts of Turkey. Asian Journal of Chemistry 22(8):6563-6568.

Udo EJ, H L Bohn, TC Tucker, 1970. Zinc adsorption by calcareous soils. Soil Science Society of America Journal 34: 405410.

Wang Z, Gao Y, 2001. Biogeochemical cycling of selenium in Chinese environments. Applied Geochemistry 16(11):13451351.

Whalen JK, Hu Q, Liu A, 2003. Compost applications increase water-stable aggregates in conventional and no-tillage systems. Soil Science Society of America Journal 67 (6):1842-1847.

Zayed AM, Terry N, 1992. Selenium volatilization in broccoli as influenced by sulfate supply. Journal of Plant Physiology 140:646-652.

Zhang Y, Frankenberger WT, 2003. Factors affecting removal of selenate in agricultural drainage water utilizing rice straw. Science of The Total Environment 305(1):207-216.

Zhu S, Liang Y, Gao D, An X, Kong F, 2017. Spraying foliar selenium fertilizer on quality of table grape (Vitis vinifera L.) from different source varieties. Scientia Horticulturae 218:87-94.

Gabos MB, Alleoni LRF, Abreu CA, 2014. Background levels of selenium in some selected Brazilian tropical soils. Journal of Geochemical Exploration 145:35-39.

Zhang HH, Wu ZF, Yang CL, Xia B, Xu DR, Yuan HX, 2008. Spatial distributions and potential risk analysis of total soil selenium in Guangdong province, China. Journal of Environmental Quality 37:780-787.

Yamada H, Kamada A, Usuki M, Yanai J, 2009. Total selenium content of agricultural soils in Japan. Soil Science and Plant Nutrition 55:616-622.

Pezzarossa B, Petruzzelli G, 2001. Selenium contamination in soil: sorption and desorption processes. In: Selim, H.S., Sparks, D.L. (Eds.), Heavy Metals Release in Soils. CRC Press, pp. 191-206.

Fordyce FM, Brereton N, Hughes J, Luo W, Lewis J, 2010. An initial study to assess the use of geological parent materials to predict the Se concentration in overlying soils and in five staple foodstuffs produced on them in Scotland. Science of The Total Environment 408:5295-5305.

Yan Dong D, Lisk DJ, Block E, Ip C, 2001. Characterization of the Biological Activity of -Glutamyl-Semethylselenocysteine, Cancer Research 61:2923-2928. 